\title{
Effect of Lithium Chloride on Serum Levels of BDNF, TNF- $\alpha$, and Wet Weight of Brain in an Animal Model of Depression
}

\author{
Marzieh Moghadas ${ }^{1,2}$, Mohammad Amin Edalatmanesh ${ }^{1,2 *}$, Mahmoud Hosseini \\ ${ }^{1}$ Department of Physiology, College of Sciences, Fars Science and Research Branch, Islamic Azad University, Fars, Iran. \\ ${ }^{2}$ Department of Physiology, College of Sciences, Shiraz Branch, Islamic Azad University, Shiraz, Iran. \\ ${ }^{3}$ Neurocognitive Research Center, School of Medicine, Mashhad University of Medical Sciences, Mashhad, Iran.
}

\section{A BSTRACT}

Introduction: Pathophysiology of depression is a controversial issue. Hippocampal lesions could lead into depression as well as to changing the levels of several cytokines, including brain-derived neurotrophic factor (BDNF) and tumor necrosis factor alpha (TNF- $\alpha$ ). The present study was aimed to investigate the mechanism of depression induced by trimethyltin (TMT) intoxication and to study the effect chronic administration of lithium chloride (Li) on depression in this animal model. Materials and Methods: The animals were divided into TMT+Li20, TMT+Li40, TMT+ Li80 and TMT+Salin groups, which were received $8 \mathrm{mg} / \mathrm{kg}$ TMT and 20, 40 or $80 \mathrm{mg} / \mathrm{kg}$ of Li or saline, respectively, for fourteen days. In order to define the depression level, the immobility time of the rats was measured in the forced swim test (FST), and tail suspension test (TST). Then, the serum level of TNF- $\alpha$, BDNF and wet weight of the brains were measured. Results: The immobility time in FST and TST was longer in the rats who received TMT, whereas the rats receiving Li showed a significantly less immobility compared to the TMT+Saline group. In addition, Li administration increased the serum level of BDNF and wet weight of the brains and decreased the TNF- $\alpha$ level compared to the TMT+Saline group. Conclusion: The decrease in BDNF or the increase in inflammation factors (especially TNF- $\alpha$ ) occurred in accompany by depression symptoms in TMT intoxication model. On the other hand, chronic administration of Li may modulate the cytokines and amelioration of behavioral symptoms.

* Corresponding Author: Mohammad Amin Edalatmanesh

E-mail: amin.edalatmanesh@gmail.com

\section{Key words:}

1. Trimethyltin Compounds

2. Lithium

3. Depression

4. Brain-Derived Neurotrophic Factor 
اثر ليتيوم كلرايد بر سطح سرمى فاكتور نوروتروفيك مشتق شده از مغز، فاكتور نكروزدهندهُ تومورى آلفا و وزن مرطوب مغز در مدل حيوانى افسردَى

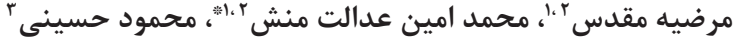 \\ ' كروه فيزيولوزى، دانشكده علوم، واحد علوم و تحقيقات فارس، دانشكاه آزاد اسلامى، فارس، ايران.

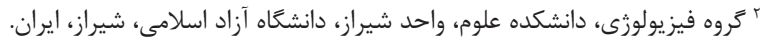

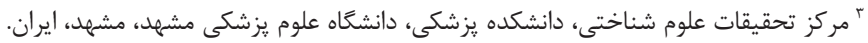

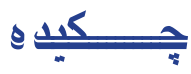

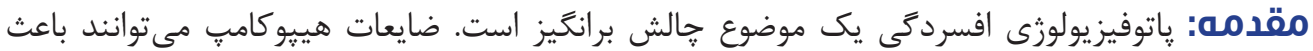

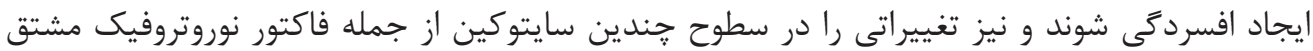

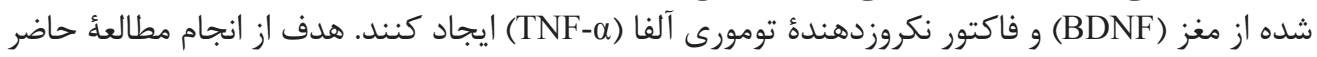

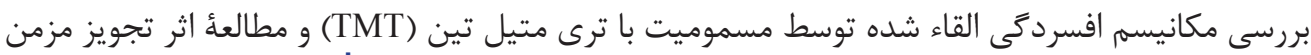

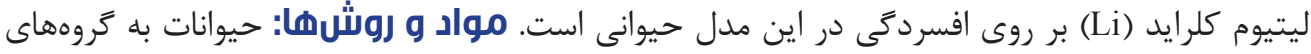

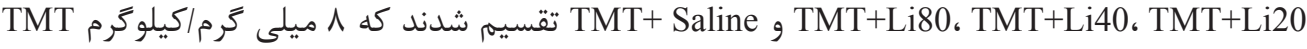

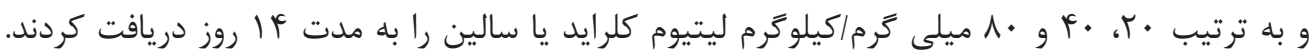

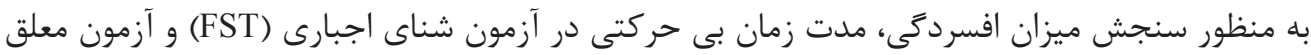

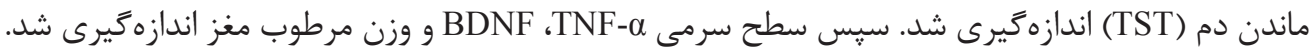

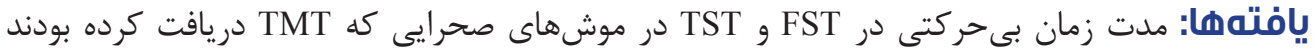

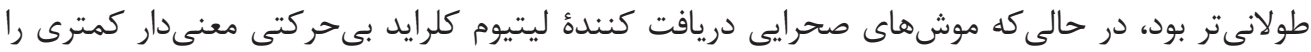

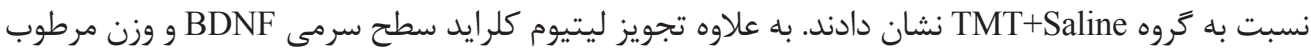

كليد وازهها: ا. تركيبات ترى متيل تين

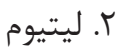

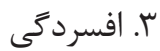
f أ. عامل نروتروفيك مشتق شده أن از مغز

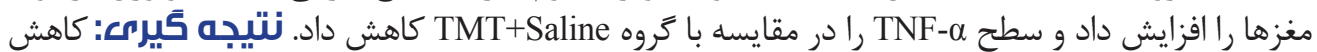
يا افزايش فاكتورهاى التهابى (به ويزه مانه

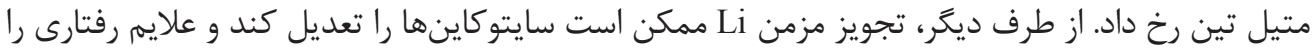

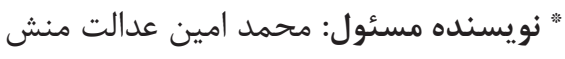

آدرس الكترونيكى: amin.edalatmanesh@gmail.com 
ياتولوزيك مانند عفونتهاى ويروسى، آرتريت روماتوئيد، سرطان

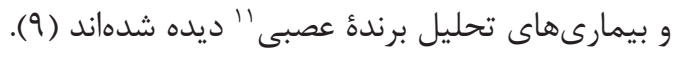

ترى متيل تين كلرايد (TMT) "ا تركيبى است كه در يلى وينيل

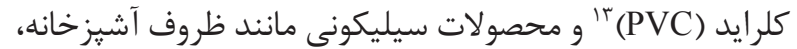

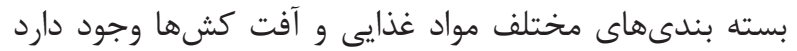

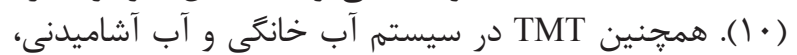

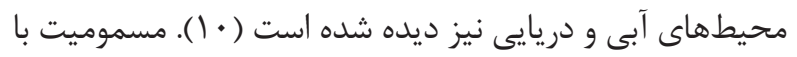

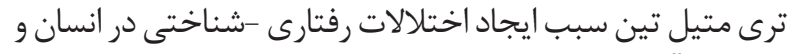

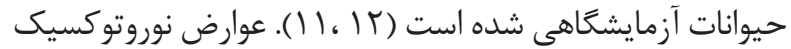

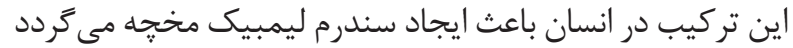

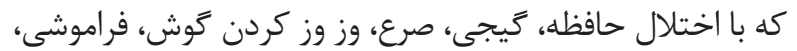

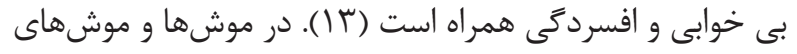

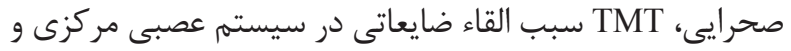

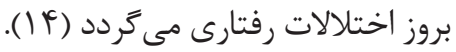

بيش از ه دهه است كه مطالعات بيش كلينيكى عملكرد ليتيوم را بر شمارى از سطوح شامل سطوح بيوشيميايى (تعيين اهداف

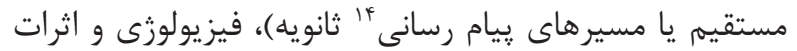

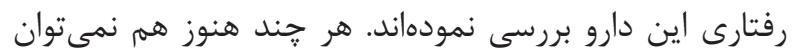

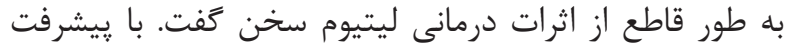

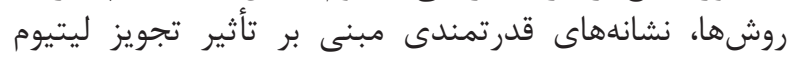

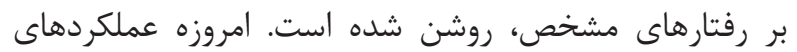

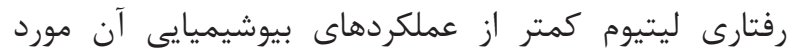

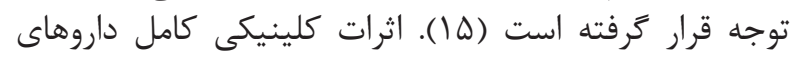

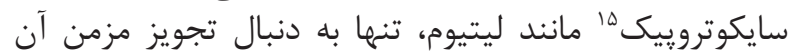

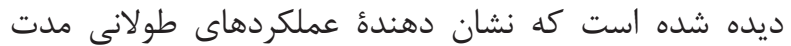

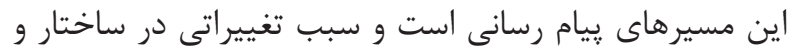

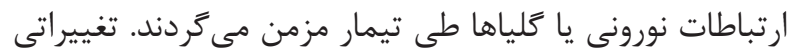

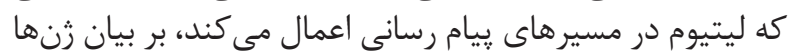

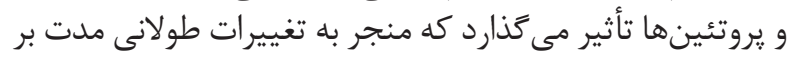

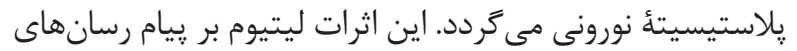

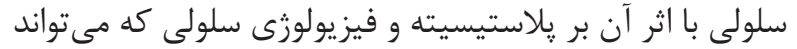

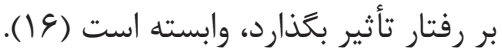

نقص در انعطاف يذيرى سلولى و سينايسى در بسيارى از اختلالات

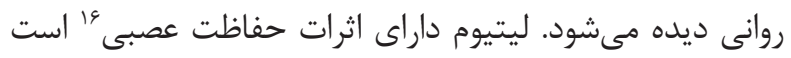

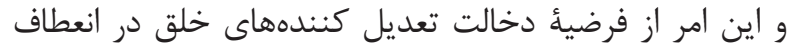

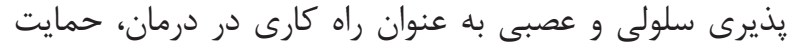

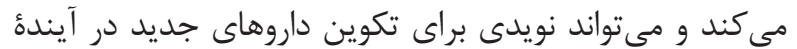

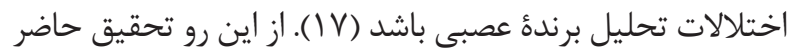

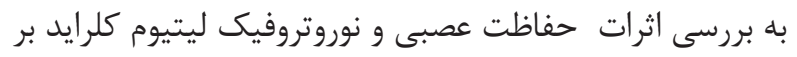

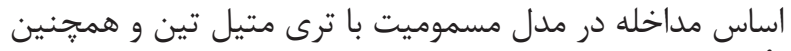

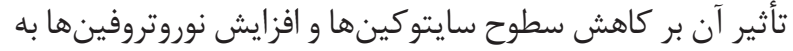

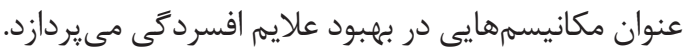

${ }^{1}$ Etiology

${ }^{2}$ Magnetic resonance imaging (MRI)

${ }^{3}$ Brain-derived neurotrophic factor (BDNF)

${ }^{4}$ Tumor necrosis factor alpha $(\mathrm{TNF} \alpha)$

${ }^{5}$ Neurotrophins (NTs)

${ }^{6}$ Nerve growth factor (NGF)

${ }^{7}$ Neurotrophin-3 (NT-3)

${ }^{8}$ Neurotrophin-4 (NT-4)

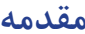

روشن ساختن اساس نوروبيولوزيكى افسردگى يكى از مهمترين

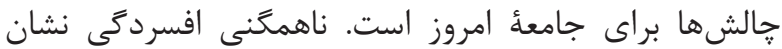

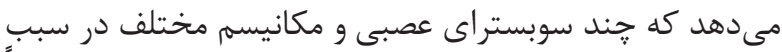

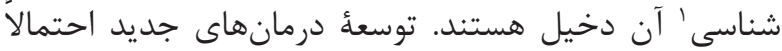

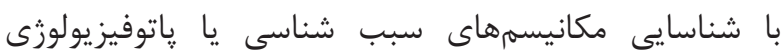

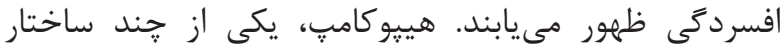

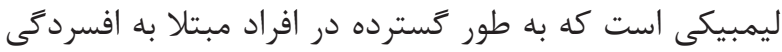

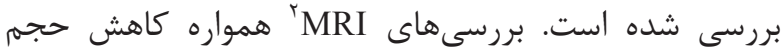

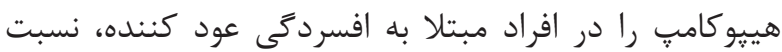

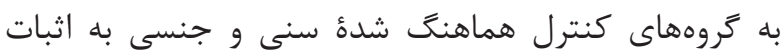

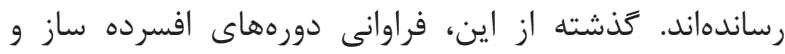

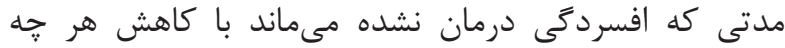

بيشتر حجم هييو كامٍ همراه است (1)

شواهد يايهاى و كلينيكى نشان مى هدهند كه افسردكى علاوه بر

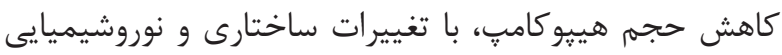

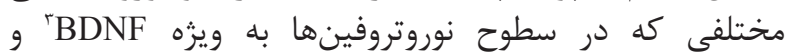

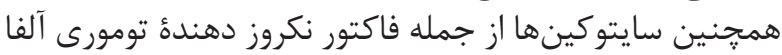
(T) (TNF- $\alpha$ )

مطالعات متعددى منجر به سازماندهى فرضيئ نوروتروفيك كافي

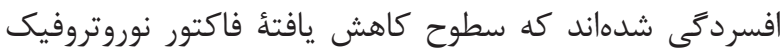

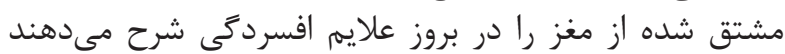

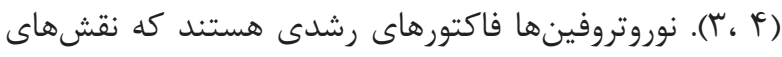

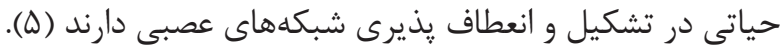

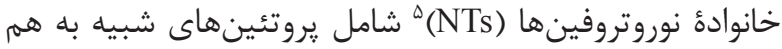

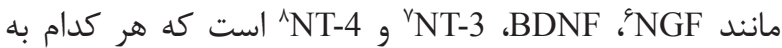

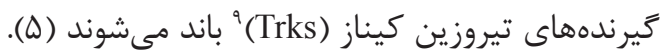
در مراحل آغازين بيمارى آلزايمر، اختلالات شناختى غالباً با

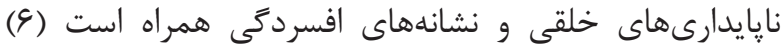

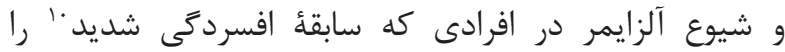

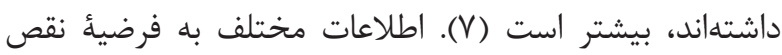

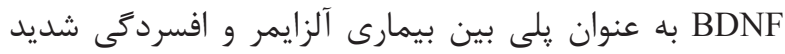

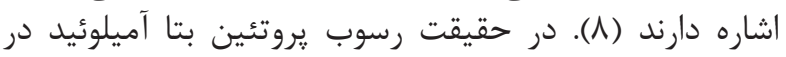

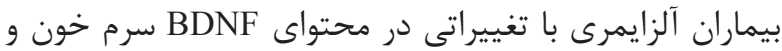
نواحى قشرى همراه بوده است.

علاوه بر تغييرات سطوح نوروتروفينى در اختلال افسردگى،

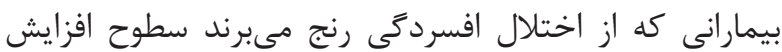

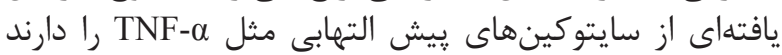

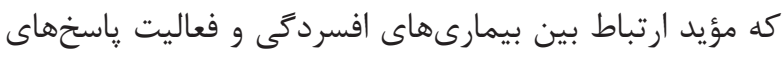

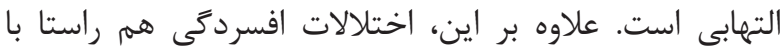

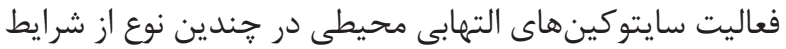

\footnotetext{
${ }^{9}$ Tyrosine kinase receptors (Trks)

${ }^{10}$ Major depression

${ }^{11}$ Neurodegenerative disorders

${ }^{12}$ Trimethyltin Chloride (TMT)

${ }^{13}$ Polyvinyl Chloride (PVC)

${ }^{14}$ Signaling pathway

${ }^{15}$ Psychotropic

${ }^{16}$ Neuroprotective
} 


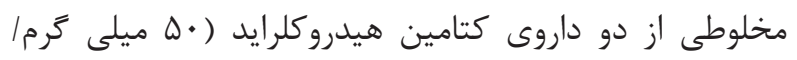

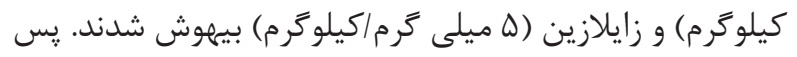

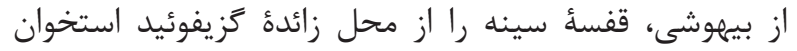

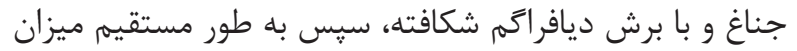

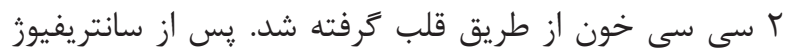

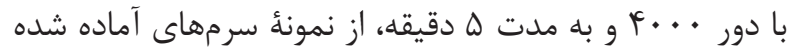

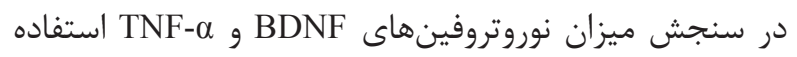

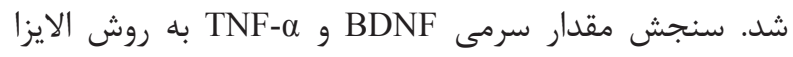

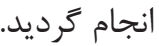

$$
\text { سنجش وزن مرطوب مغز }
$$

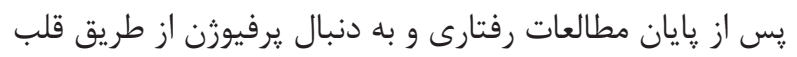

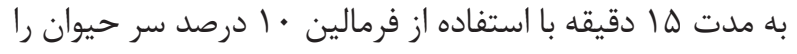

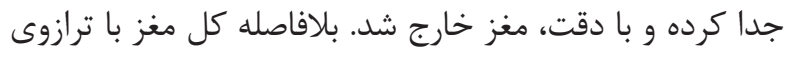

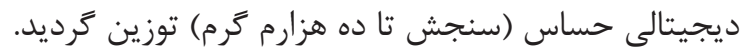

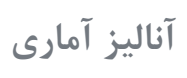

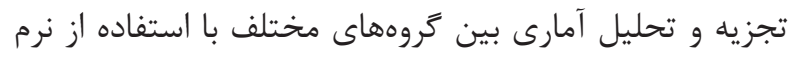

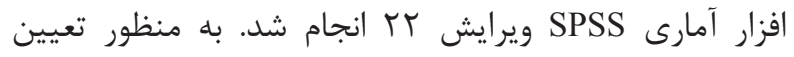

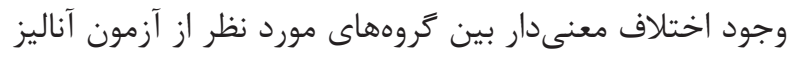

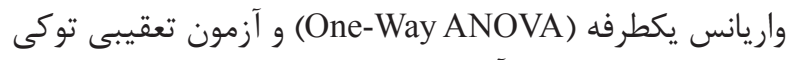

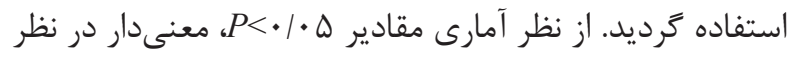

كرفته شد.

بافته ها

$$
\text { آزمون شناى اجبارى }
$$

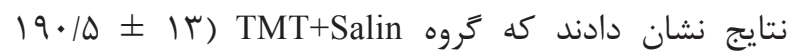

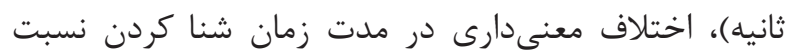

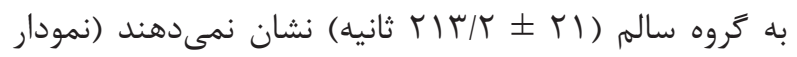

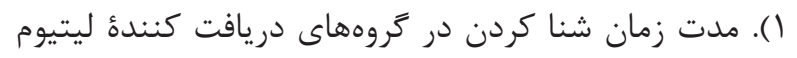

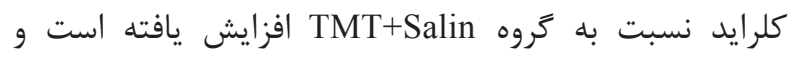

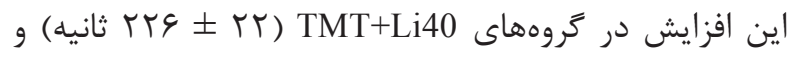
(P) TMT+Li80

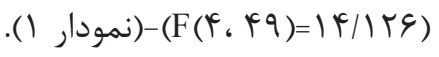

تيمار با ترى متيل تين به طور قابل توجهى مدت ردات زمان

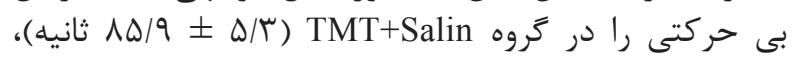

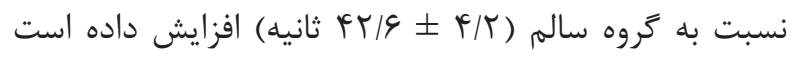

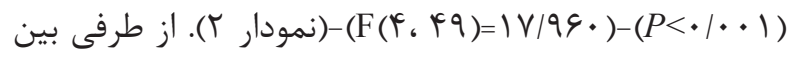
كروه TMT+Li40

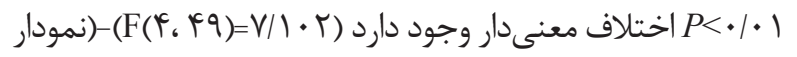

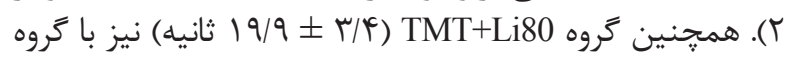

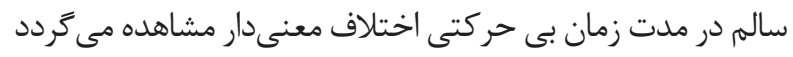

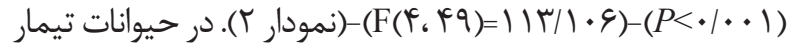

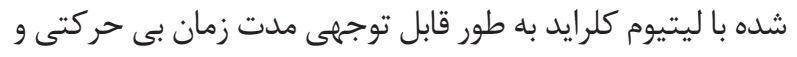

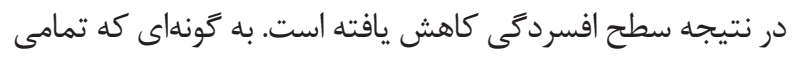

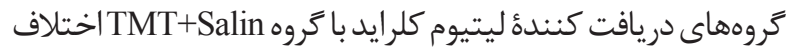

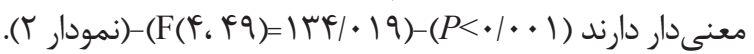

مواد و روشها

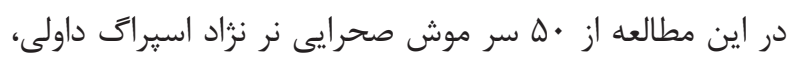

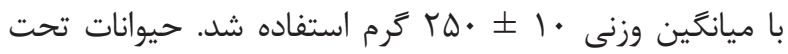
شرايط استاندارد دمايى (r)

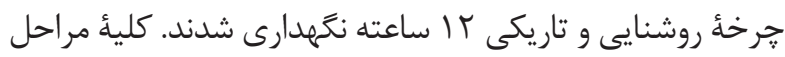

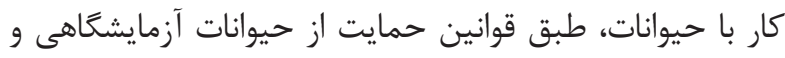

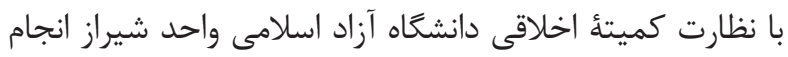

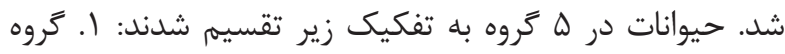

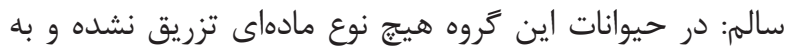

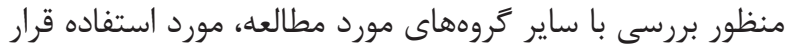

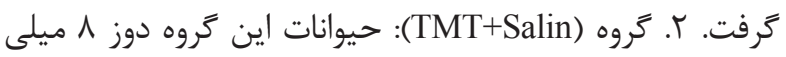

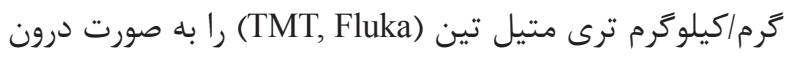

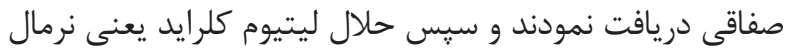

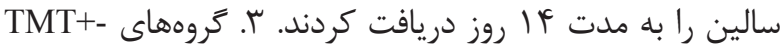

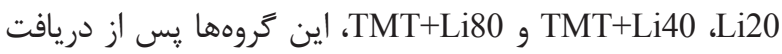

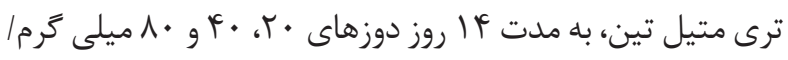
كيلوكرم از ليتيوم كلرايد را دريافت نمودند. ترون.

$$
\text { آزمون شناكردن اجبارى }
$$

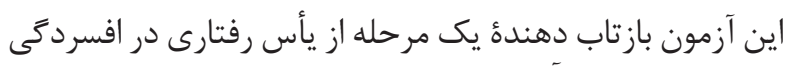

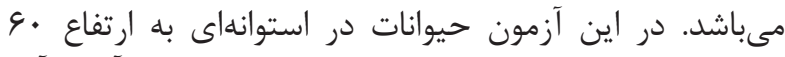

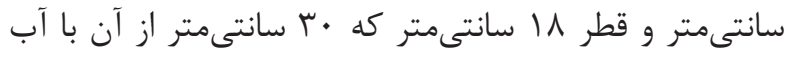

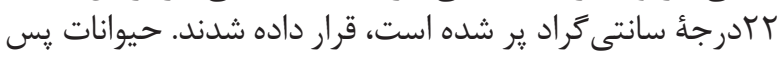

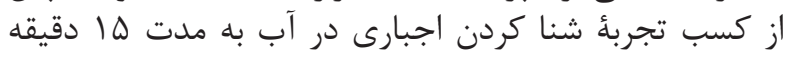

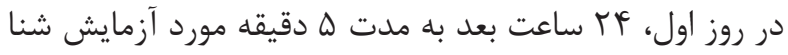

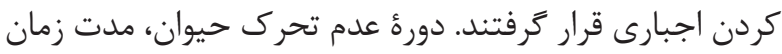

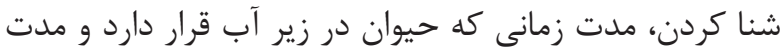

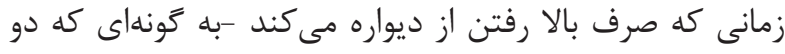

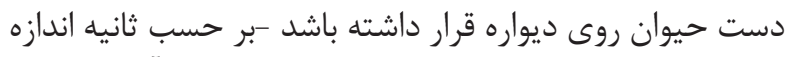

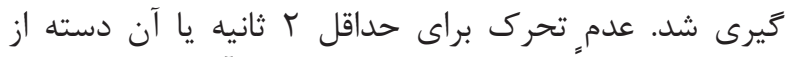

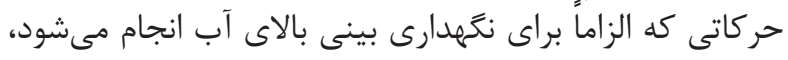

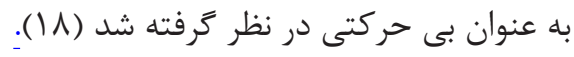

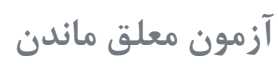

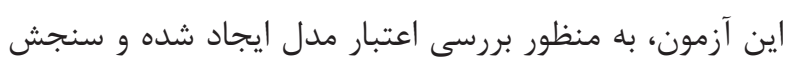

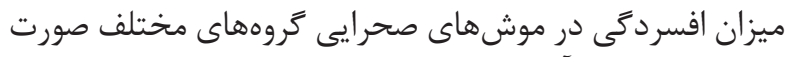

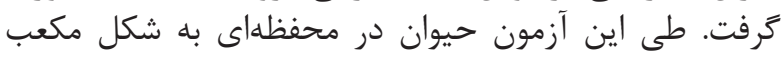

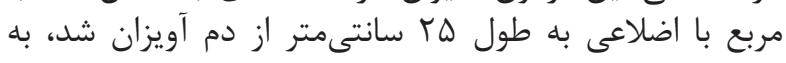
طورى كه دو دست حيوان روى كف كف ماز

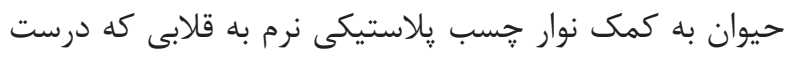

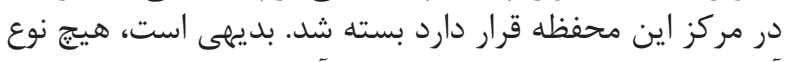

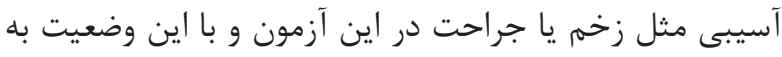

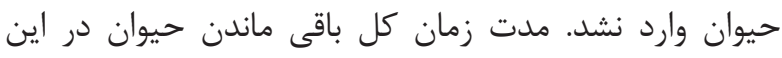

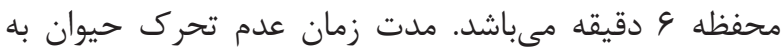

$$
\begin{aligned}
& \text { وسيلة آزمايشكر ثبت كرديد. } \\
& \text { آزمون هاى بيوشيميايى }
\end{aligned}
$$

جهت تهيئ نمونه سرم خون، حيوانات با تزريق درون صفاقى بئى 
تحرك (شنا كردن)

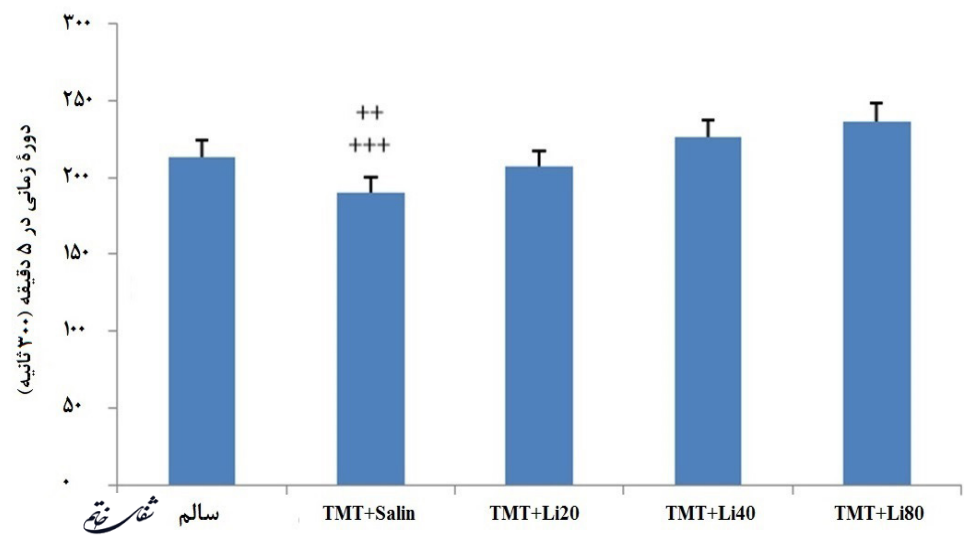

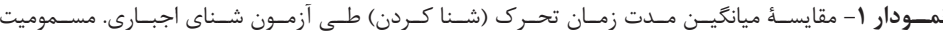

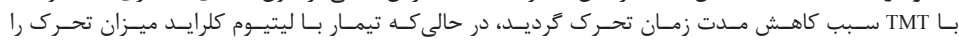

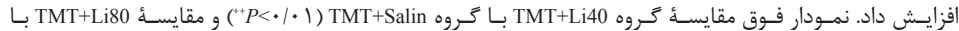

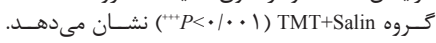

بى حركتى

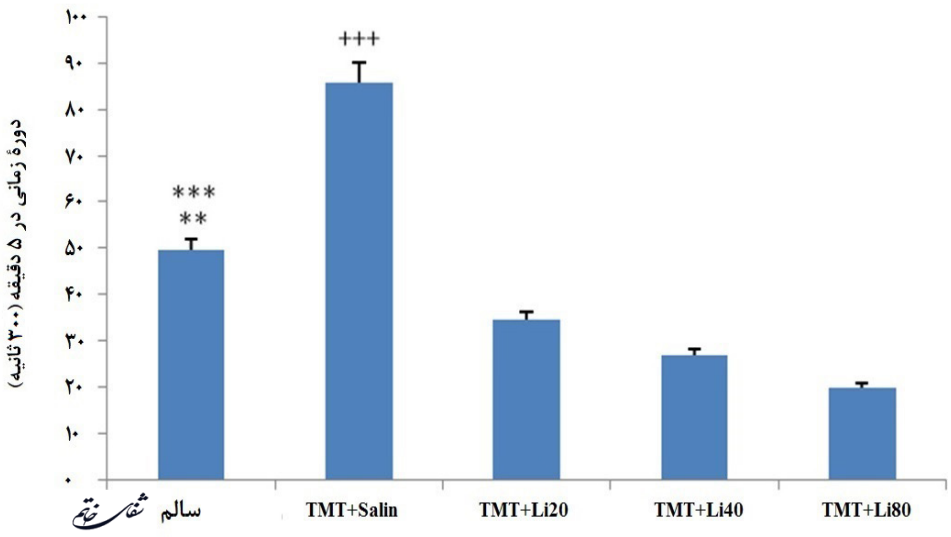

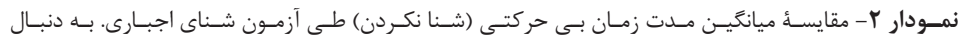

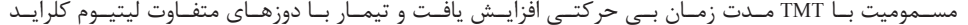

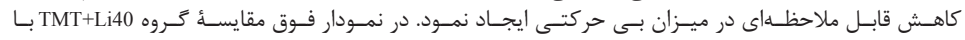

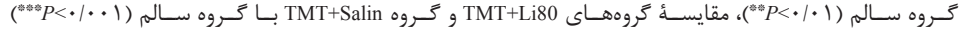

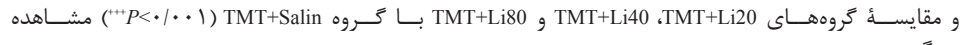

آزمون معلق ماندن

مطالعهُ آناليز واريانس يكطرفه وجود اختلاف كاملاً معنى دارى

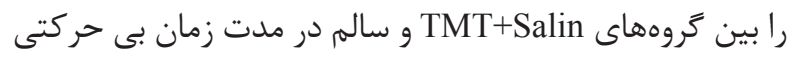

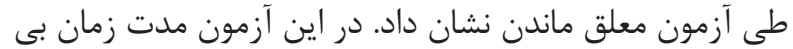

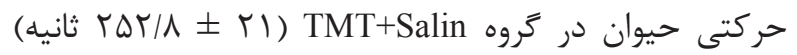

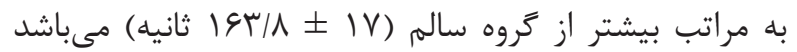

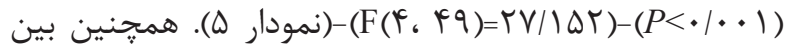
گروههاى دريافت كننده ليتيوم كلرايد (كروه TMT+Li20:

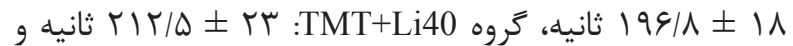
كروه TMT+Li80: سا معنى

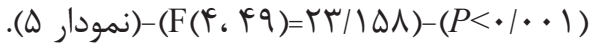

مدت زمان بالا رفتن از ديواره نيز در گروه هt

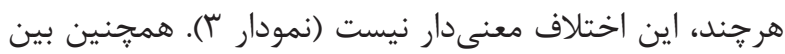

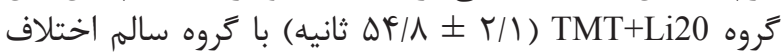

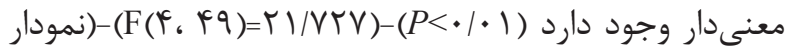
Y

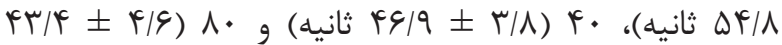

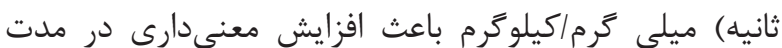

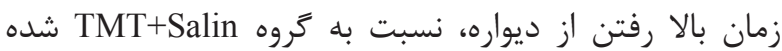

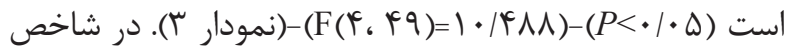

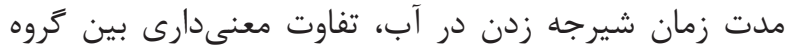

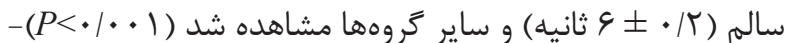

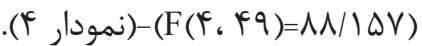




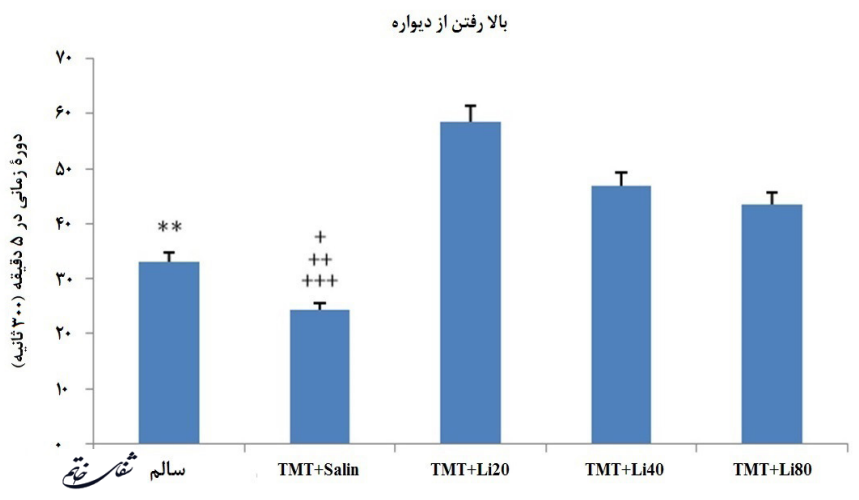

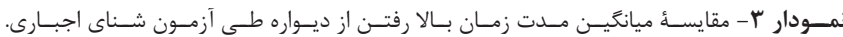

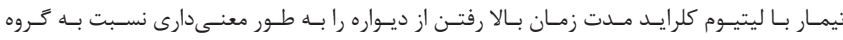
TMT+Salin

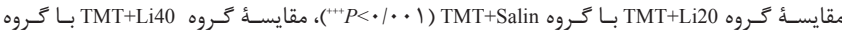

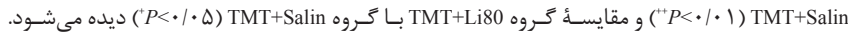

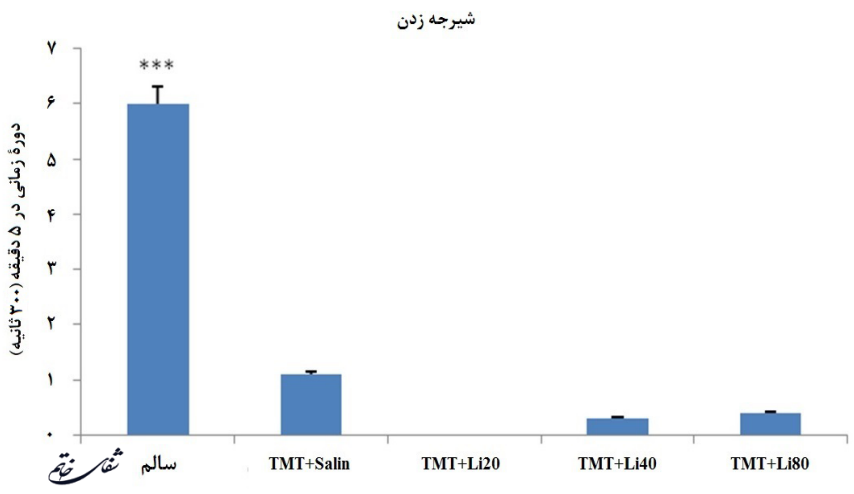

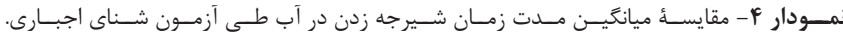

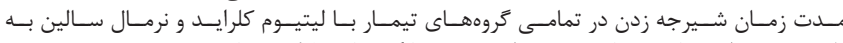

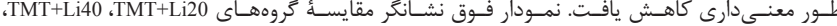
بـ TMT+Salin و TMT+Li80

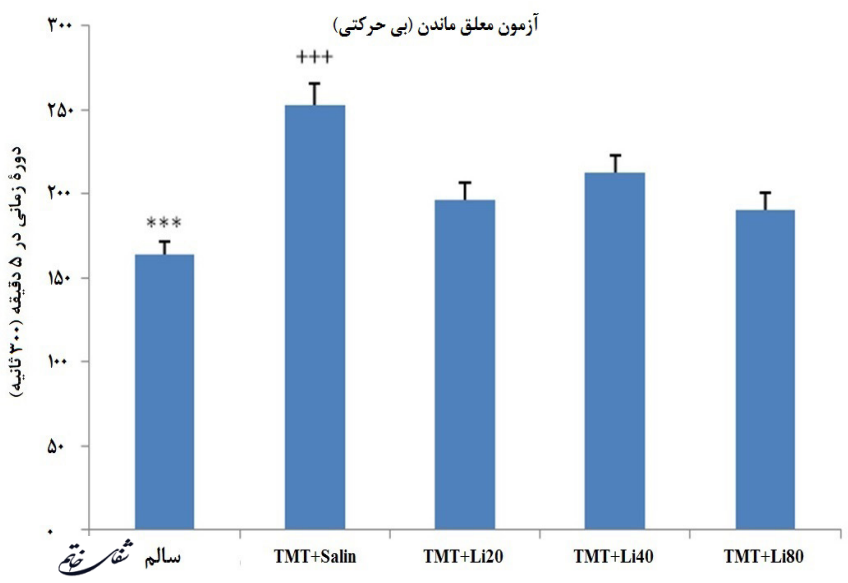

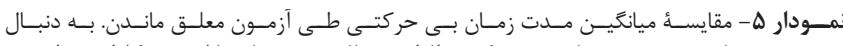

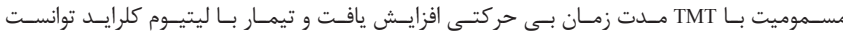

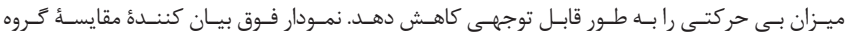

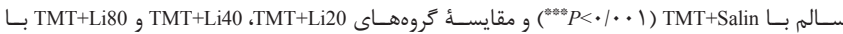
ك

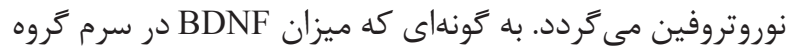
آزمون هاى بيوشيميايى

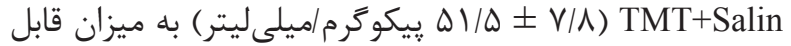

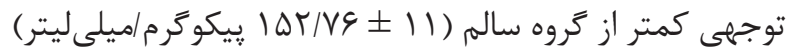
نتايج حاصل از مقائ مقايسٔ ميانكَين سطح سرمى فاكتور

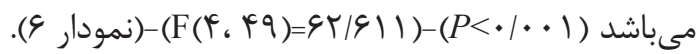

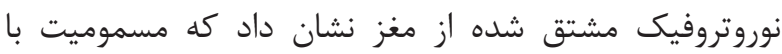

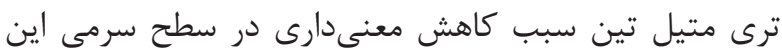



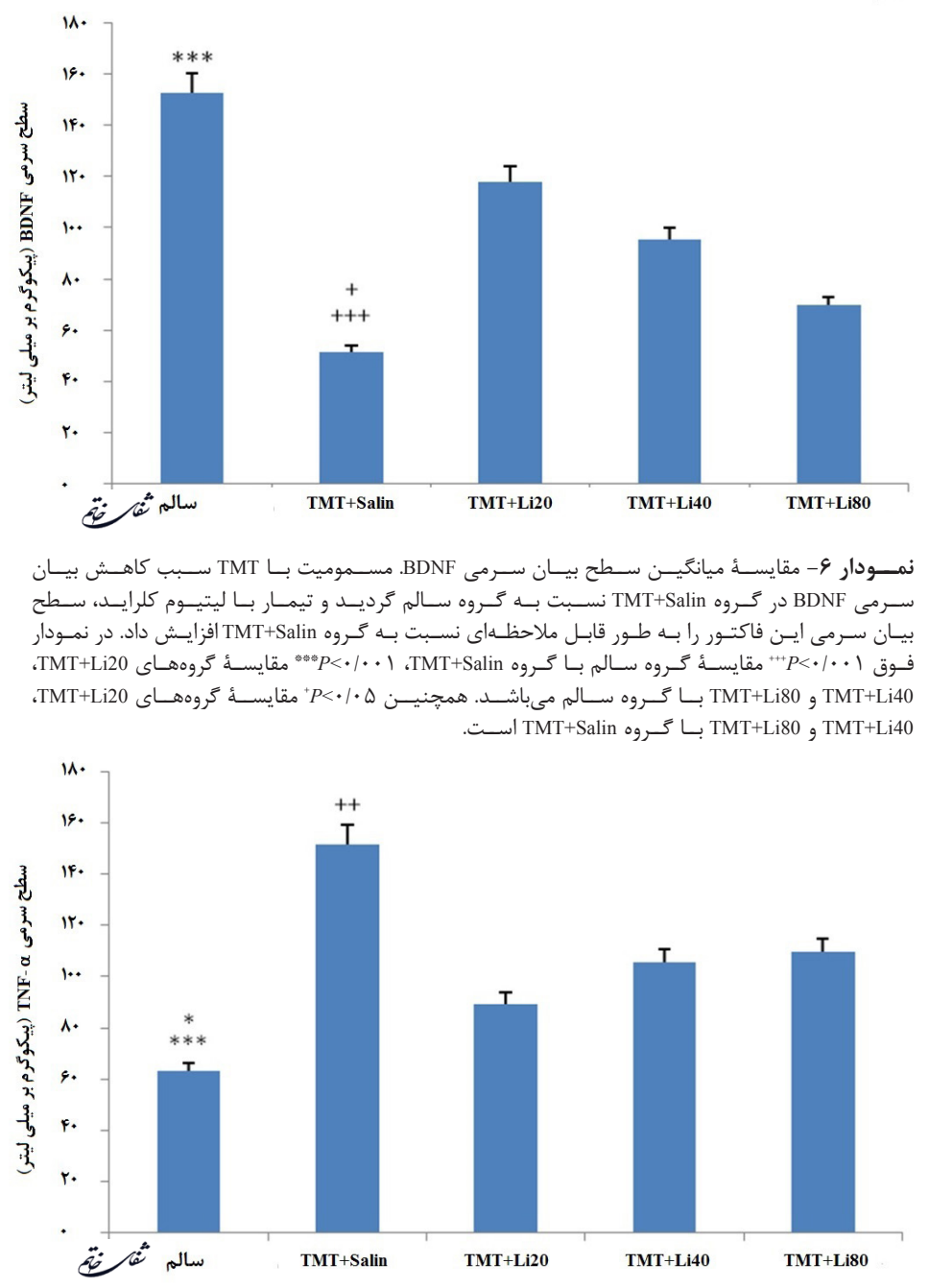

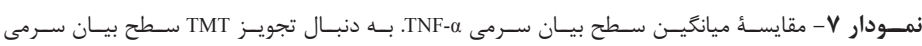

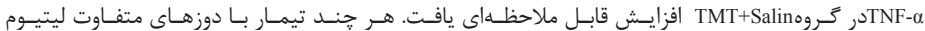

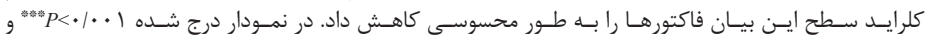

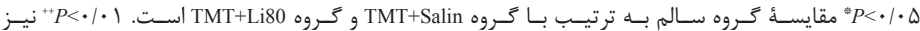

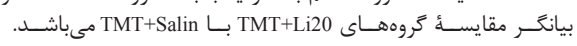

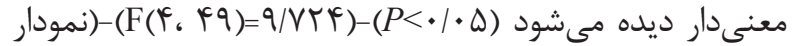

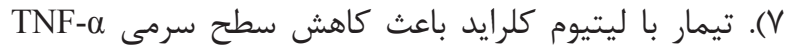

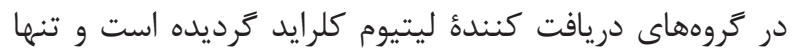

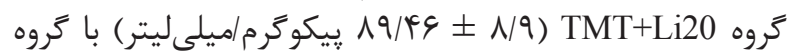
₹q)=| اختلاف معنى TMT+Salin (نمودار (F) ( F)

$$
\text { سنجش وزن مرطوب مغز }
$$

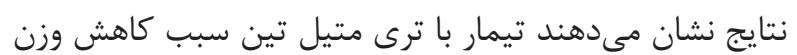

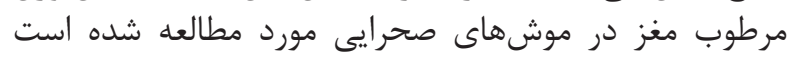

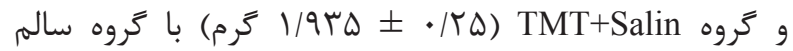
(اسT|•

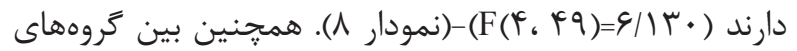

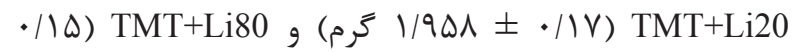
l/qRV \pm

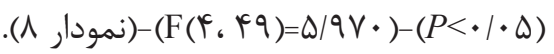

اين در حالى است كه تيمار با ليتيوم كلرايد سبب افزايش قابل توجهى (كروه TMT+Li20: IV

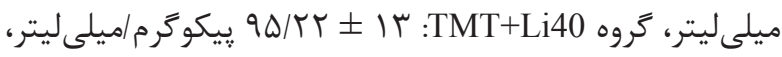

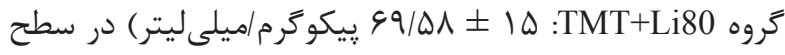

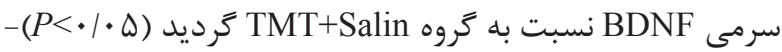

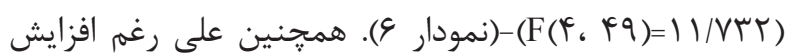
قابل توجه سطح BDNF در گرووهاى دريافت كننده ليتيوم كلرايد نسبت به گروه TMT+Salin ميزان MDNF

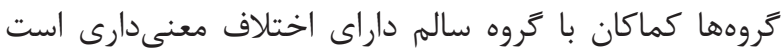

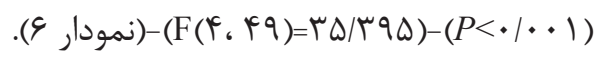
از طرفى، مسموميت با ترى متيل تين باعث افزايش معنى دارى در

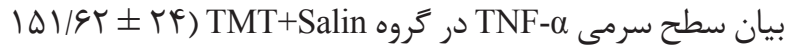

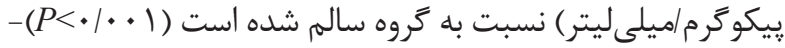

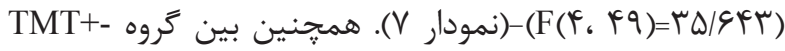
Li80 


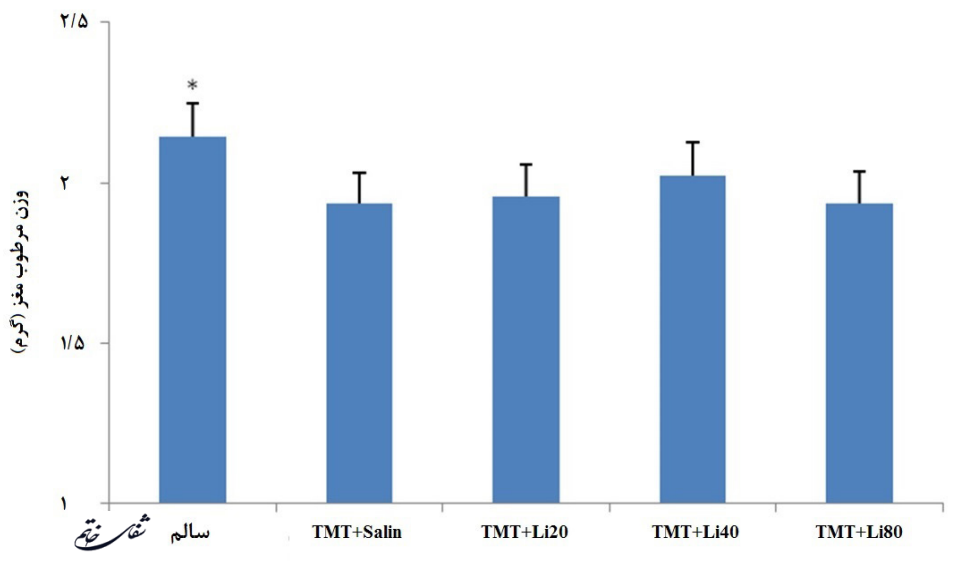

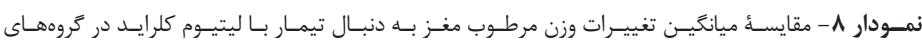

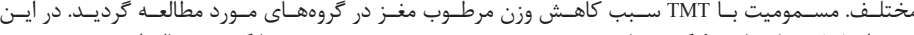

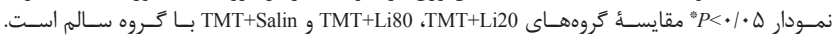

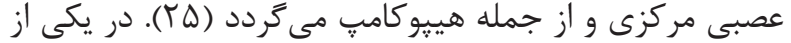

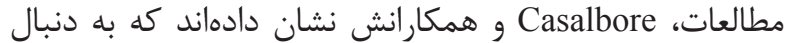

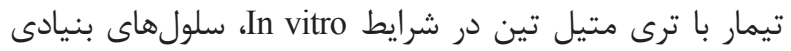

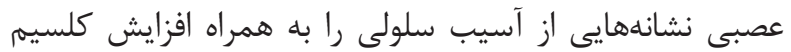

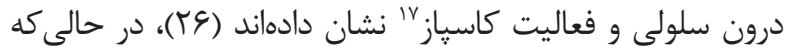

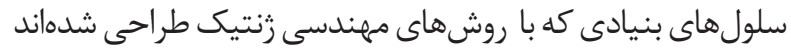

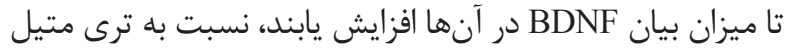

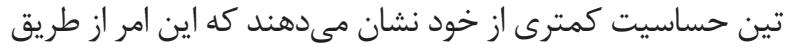

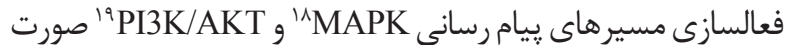

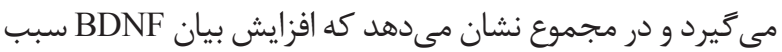

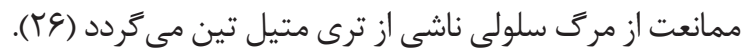

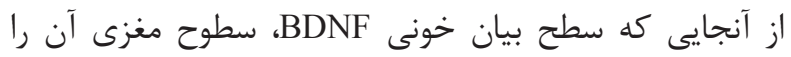

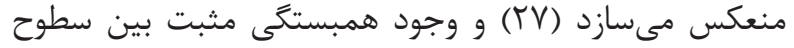

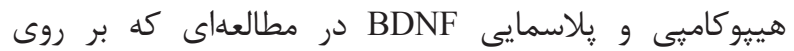

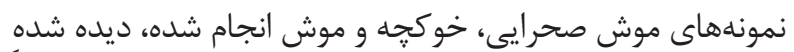

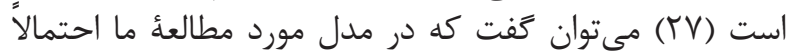

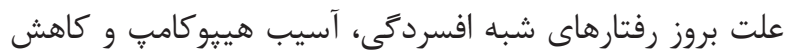

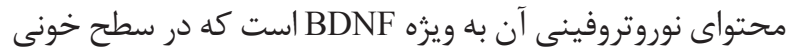

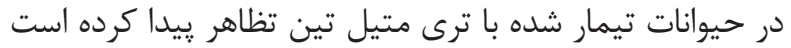

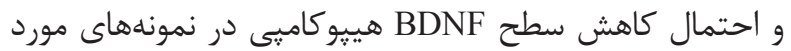

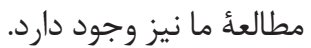

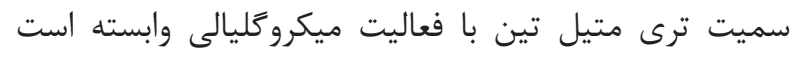

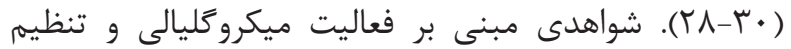

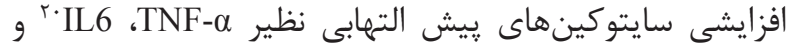

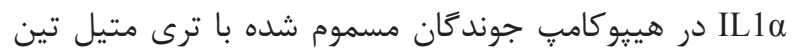

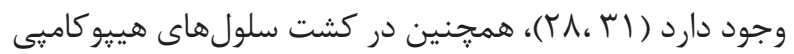

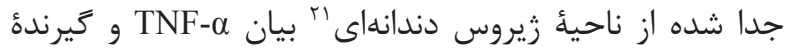

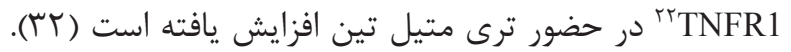

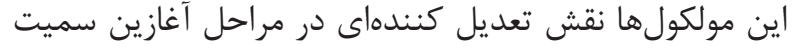
عصبى با واسطة ترى متيل تين دارند (سآ).

\footnotetext{
${ }^{17}$ Caspase

${ }^{18}$ Mitogen-activated protein kinases (MAPK)

${ }_{19}$ Phosphoinositide 3-kinase/ Protein kinase B (PKB), also known as Akt
}

بحث و نتيجه كَيرى در اين مطالعه آزمايشكاهى اثرات تجويز ترى متيل تين و فرايند

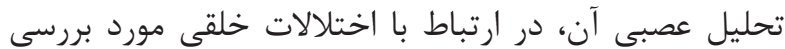

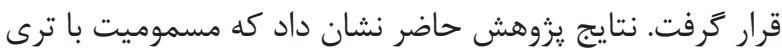

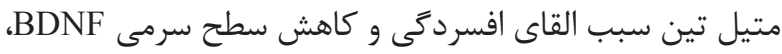

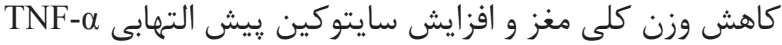

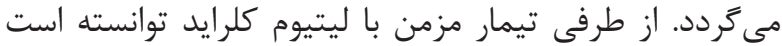

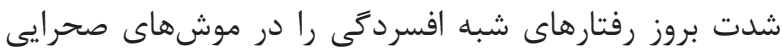

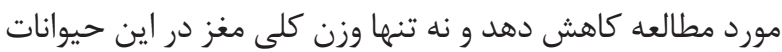

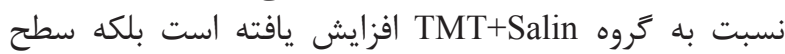
سرمى BDNF و بره

اكر جه بسيارى از مطالعات به اثرات سميت عصبى و عملكر دهاى

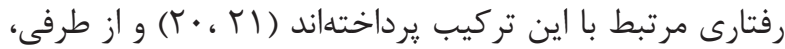

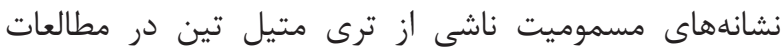

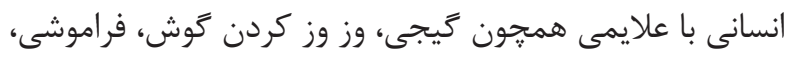

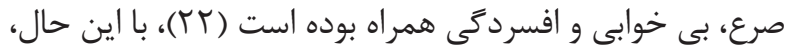

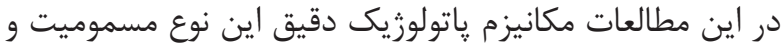

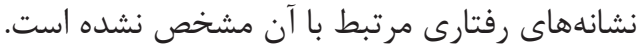

هر جند مطالعات آزمايشعاهى به بر برسى اثرات تجويز ترى متيل

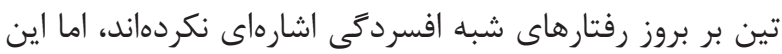

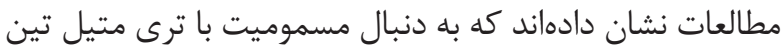

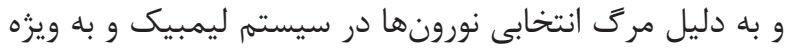

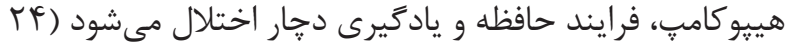

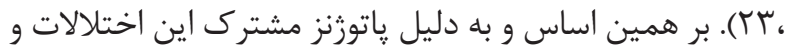

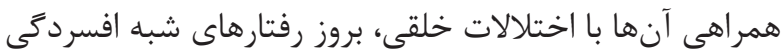

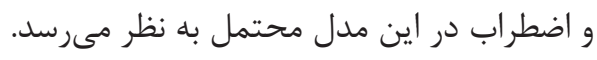
مطالعاتى كه در مورد تحليل عصبى ناشى از ترى متيل تين تين تين تئن

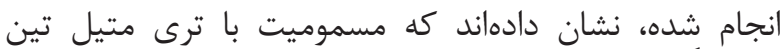

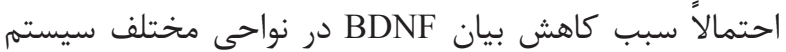

\footnotetext{
${ }^{20}$ Interleukin 6

${ }^{21}$ Dentate gyrus

${ }^{22}$ Tumor necrosis factor receptor 1 (TNFR1)
} 
ترى متيل تين سبب كاهش محتواى BDNF در مغرد مغز به ويه ويزه

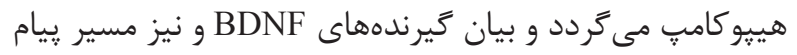

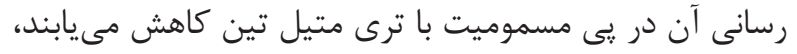

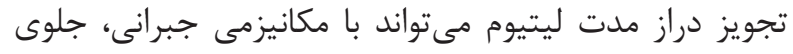

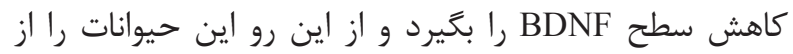

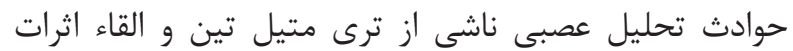

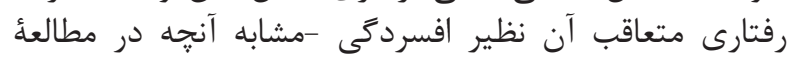
حاضر ديده شده است -مصون نكاه دارد.

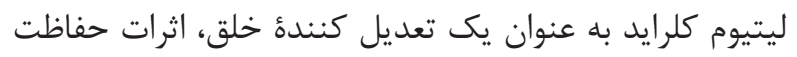

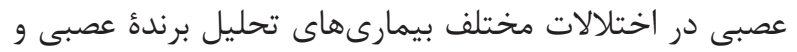

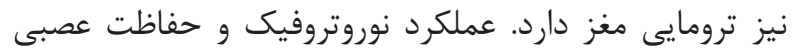

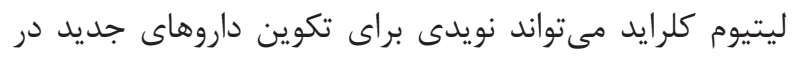

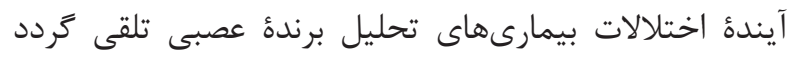

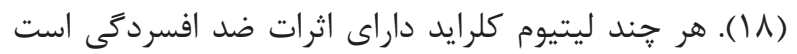

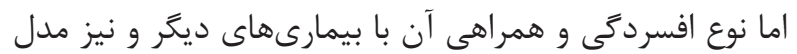

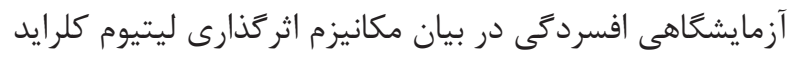

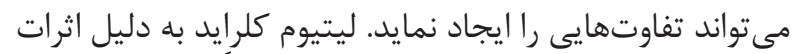

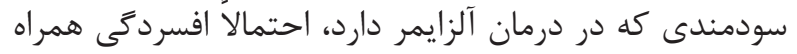

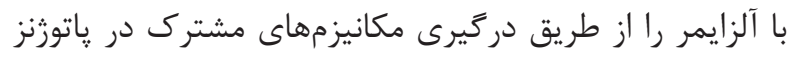

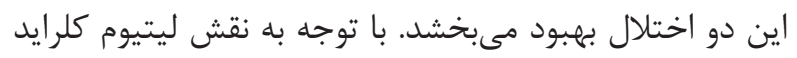

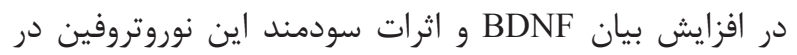

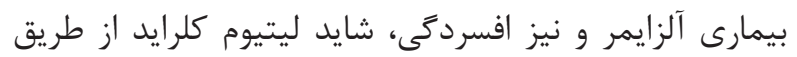

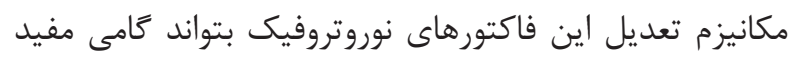

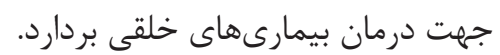

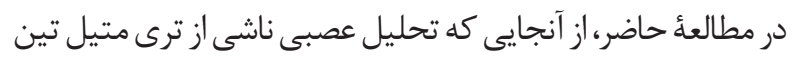

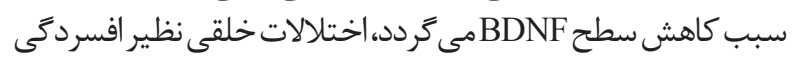

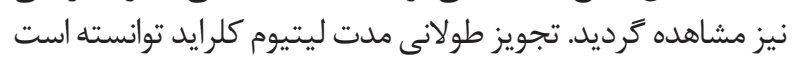

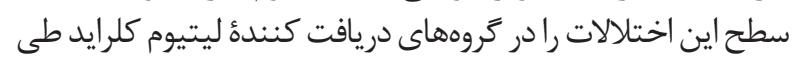

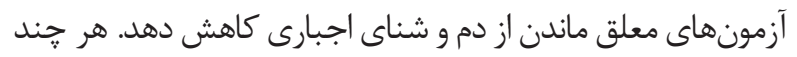

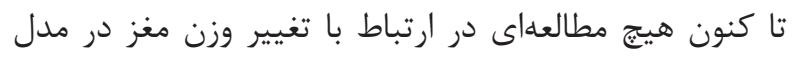

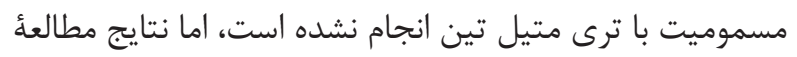

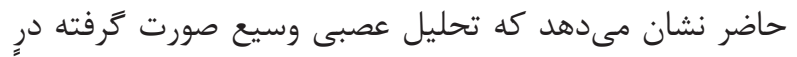

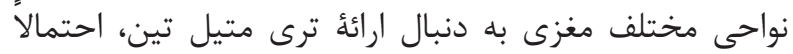

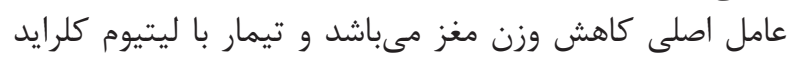

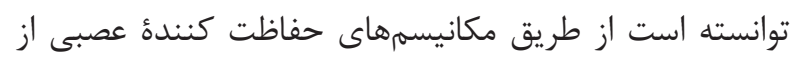
اين كاهش جلوكيرى نمايد.

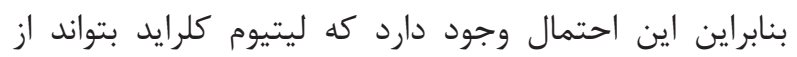

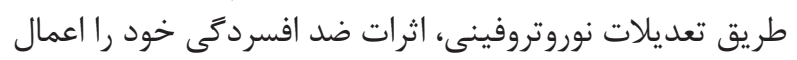

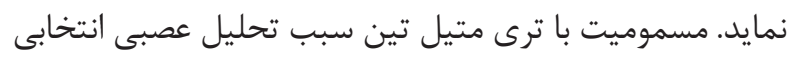

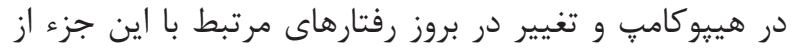

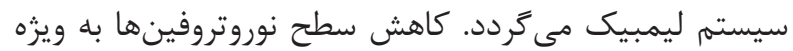

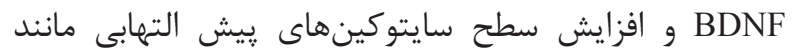
اختالات جمF- $\alpha$

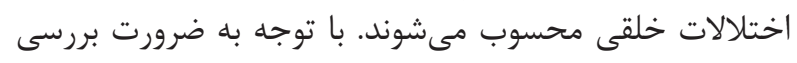

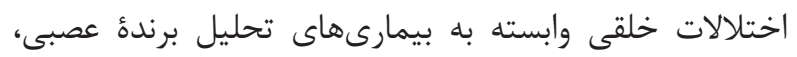
${ }^{23}$ Frontal cortex
به دنبال تيمار با ترى متيل تين در موشهاى صحرايى مورد

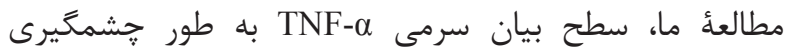

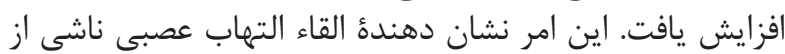

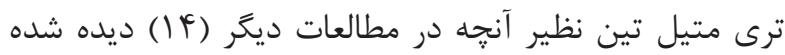

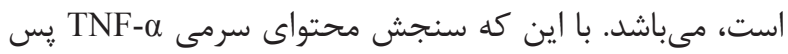

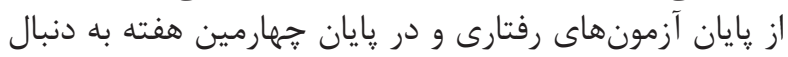

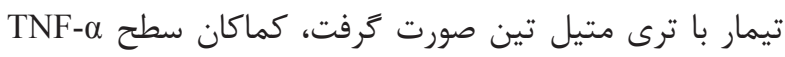

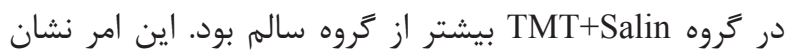

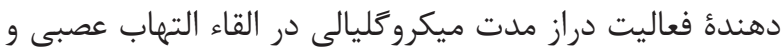

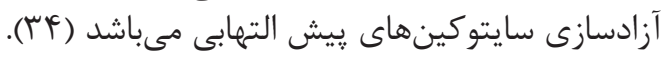

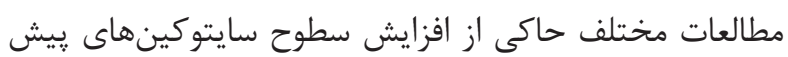

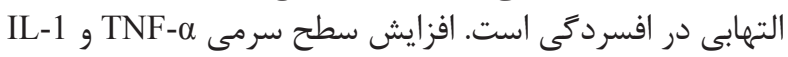

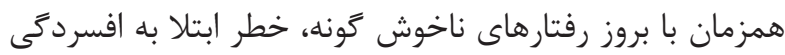

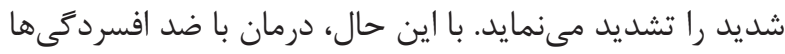

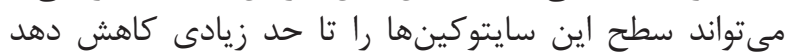

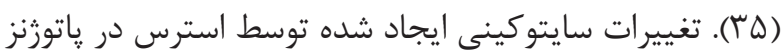

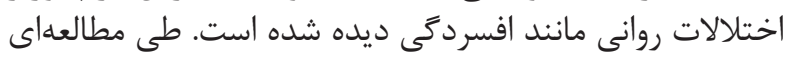

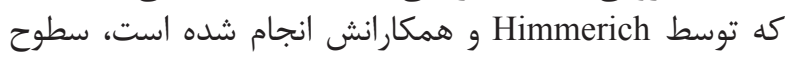

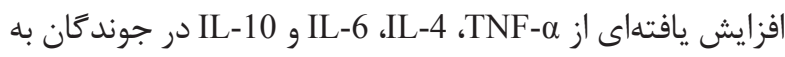

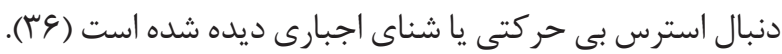

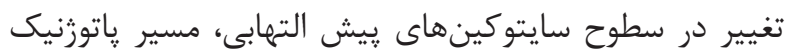

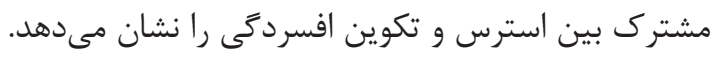

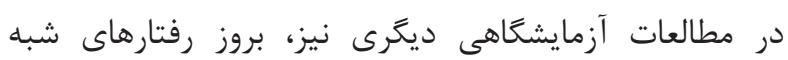

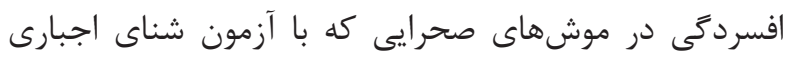

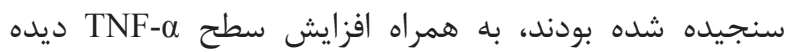

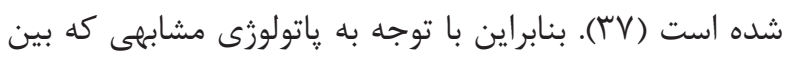

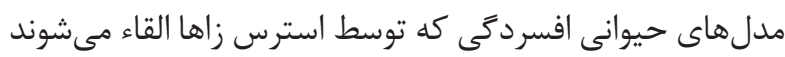

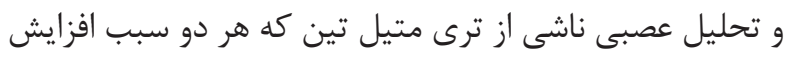

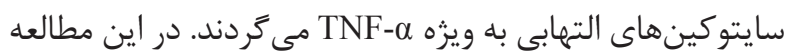

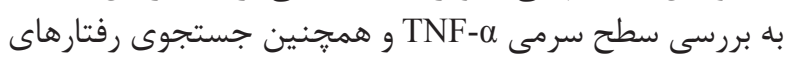

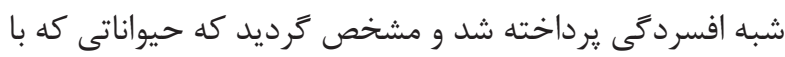

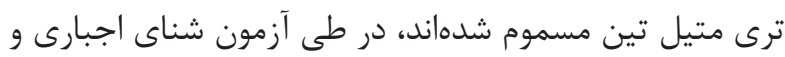

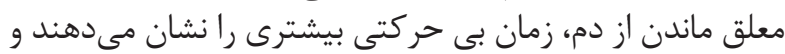
سطوح بالاترى از اين سايتو كين ييش التهابى بيش (TNF-

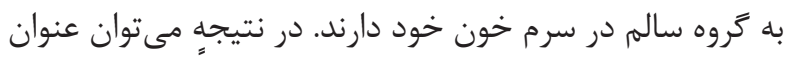

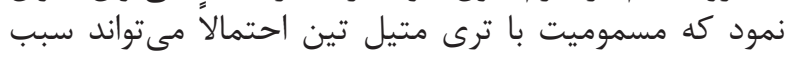

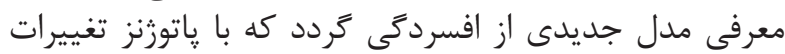

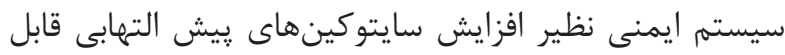

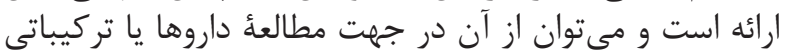

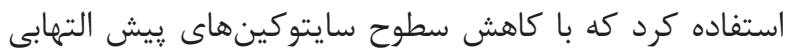

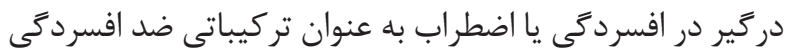

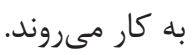

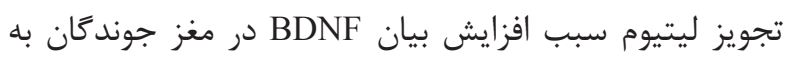

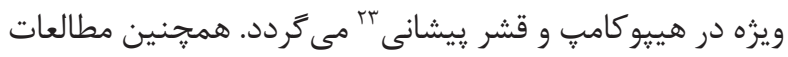

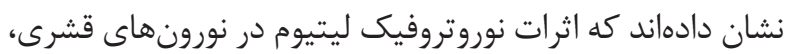

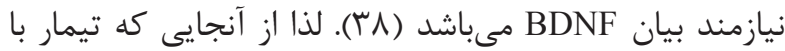




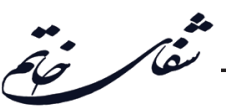

افسردكى را به دنبال تجويز دراز مدت با ليتيوم كلرايد در مدل

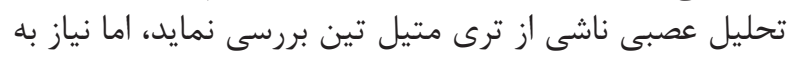

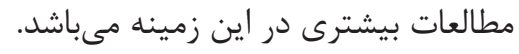

$$
\text { تشكر و قدردانى }
$$

نويسندگان بابت حمايت مالى از معاونت يزوهشى دانشعاه آزاد اسلامى واحد شيراز تقدير به عمل مى آورند.

1. Spiegel D, Loewenstein RJ, Lewis-Fernández R, Sar $\mathrm{V}$, Simeon D, Vermetten E, et al. Dissociative disorders in DSM-5. Depress Anxiety. 2011; 28: 824-52.

2. Jiang C, Salton SR. The role of neurotrophins in major depressive disorder. Transl Neurosci. 2013; 1: 46-58.

3. Castren E, Voikar V, Rantamaki T. Role of neurotrophic factors in depression. Curr Opin Pharmacol. 2007; 7:18-21.

4. Duman RS, Monteggia LM. A neurotrophic model for stressrelated mood disorders. Biol Psychiatry. 2006; 59: 1116-27.

5. Huang EJ, Reichardt LF. Trk receptors: roles in neuronal signal transduction. Ann Rev Biochem. 2003; 72: 609-42.

6. Assal F, Cummings JL. Neuropsychiatric symptoms in the dementias. Curr Opin Neurol. 2002; 15: 445-50.

7. Kessing LV, Andersen PK. Does the risk of developing dementia increase with the number of episodes in patients with depressive disorder and in patients with bipolar disorder? J Neurol Neurosurg Psychiatry. 2004; 75: 1662-6.

8. Tsai SJ. Brain-derived neurotrophic factor: a bridge between major depression and Alzheimer's disease? Med Hypotheses. 2003; 61: 110-3.

9. Kim YK, Na KS, Shin KH, Jung HY, Choi SH, Kim JB. Cytokine imbalance in the pathophysiology of major depressive disorder. Prog Neuropsychopharmacol Biol Psychiatry. 2007; 31: 1044-53.

10. Gomez FD, Apodaca P, Holloway LN, Pannell KH, Whalen MM. Effect of a series of triorganotins on the immune function of human natural killer cells. Environ Toxicol Pharmacol. 2007; 23: 18-24.

11. Hlinak Z, Krejci I, Hynie S, Klenerova V. Dipeptide "alaptide" prevented impairments in spontaneous behavior produced with trimethyltin in male rats. Neuro Endocrinol Lett. 2008; 29: 917-23.

12. Kim JK, Bae H, Kim MJ, Choi SJ, Cho HY, Hwang $\mathrm{HJ}$, et al. Inhibitory effect of Poncirus trifoliate on acetylcholinesterase and attenuating activity against
مدل تحليل عصبى ناشى از ترى متيل تين مى تواند نقشى راني

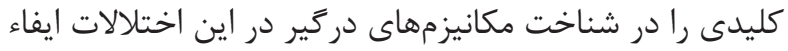

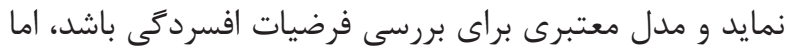

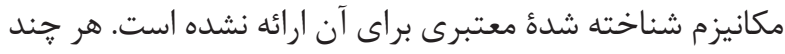

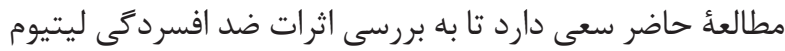

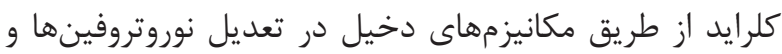

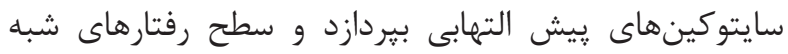

$$
\text { منابع }
$$

trimethyltin-induced learning and memory impairment. Biosci Biotechnol Biochem. 2009; 73: 1105-12.

13. Saary MJ, House RA. Preventable exposure to trimethyl tin chloride: a case report. Occup Med. 2002; 52: 227-30.

14. Reese BE, Davidson C, Billingsley ML, Yun J. Protein kinase $\mathrm{C}$ epsilon regulates tumor necrosis factoralpha-induced stannin gene expression. J Pharmacol Exp Ther. 2005; 314: 61-9.

15. O'Donnell KC, Gould TD. The Behavioral Actions of Lithium in Rodent Models: Leads to Develop Novel Therapeutics. Neurosci Biobehav Rev. 2007; 31: 932-62.

16. Einat H, Manji HK. Cellular Plasticity Cascades: Genes-To-Behavior Pathways in Animal Models of Bipolar Disorder. Biol Psychiatry. 2006; 59: 1160-71.

17. Petit-Demouliere B, Chenu F, Bourin M. Forced swimming test in mice: a review of antidepressant activity. Psychopharmacology (Berl). 2005; 177: 245-55.

18. Kastenberger I, Lutsch C, Herzog H, Schwarzer C. Influence of Sex and Genetic Background on AnxietyRelated and Stress-Induced Behaviour of ProdynorphinDeficient Mice. PLoS One. 2012; 7: e34251.

19. Ma XC, Dang YH, Jia M, Ma R, Wang F, Wu J, et al. Long-Lasting Antidepressant Action of Ketamine, but Not Glycogen Synthase Kinase-3 Inhibitor SB216763, in the Chronic Mild Stress Model of Mice. Plos One. 2013; 8: e56053.

20. Yan XB, Hou HL, Wu LM, Liu J, Zhou JN. Lithium regulates hippocampal neurogenesis by ERK pathway and facilitates recovery of spatial learning and memory in rats after transient global cerebral ischemia. Neuropharmacology. 2007; 53: 487-95.

21. Jung EY, Lee MS, Ahn CJ, Cho SH, Bae H, Shim I. The neuroprotective effect of gugijihwang-tang on trimethyltin-induced memory dysfunction in the rat. Evid Based Complement Alternat Med. 2013; 2013: 542081.

22. Geloso MC, Corvino V, Michetti F. Trimethyltininduced hippocampal degeneration as a tool to investigate neurodegenerative processes. Neurochemistry Int. 2011; 
58: $729-38$.

23. Mignini F, Nasuti C, Artico M, Giovannetti F, Fabrizi C, Fumagalli L, et al. Effects of trimethyltin on hippocampal dopaminergic markers and cognitive behaviour. Int J Immunopathol Pharmacol. 2012; 25: 1107-19.

24. Park HJ, Shim HS, Ahn YH, Kim KS, Park KJ, Choi WK, et al. Tremella fuciformis enhances the neurite outgrowth of PC12 cells and restores trimethyltininduced impairment of memory in rats via activation of CREB transcription and cholinergic systems. Behav Brain Res. 2012; 229: 82-90.

25. Corvino V, Marchese E, Giannetti S, Lattanzi W, Bonvissuto D, Biamonte F, et al. The neuroprotective and neurogenic effects of neuropeptide $\mathrm{Y}$ administration in an animal model of hippocampal neurodegeneration and temporal lobe epilepsy induced by trimethyltin. J Neurochem. 2012; 122: 415-26.

26. Casalbore P, Barone I, Felsani A, D’Agnano I, Michetti F, Maira G, et al. Neural stem cells modified to express BDNF antagonize trimethyltin-induced neurotoxicity through $\mathrm{PI} 3 \mathrm{~K} / \mathrm{Akt}$ and MAP kinase pathways. J Cell Physiol. 2010; 224: 710-21.

27. Klein AB, Williamson R, Santini MA, Clemmensen C, Ettrup A, Rios M, et al. Blood BDNF concentrations reflect brain-tissue BDNF levels across species. Int $\mathrm{J}$ Neuropsychopharmacol. 2011; 14(3): 347-53.

28. Harry GJ1, Funk JA, Lefebvre d'Hellencourt C, McPherson CA, Aoyama M. The type 1 interleukin 1 receptor is not required for the death of murine hippocampal dentate granule cells and microglia activation. Brain Res. 2008; 1194: 8-20.

29. Huong NQ, Nakamura Y, Kuramoto N, Yoneyama M, Nagashima R, Shiba $\mathrm{T}$, et al. Indomethacin ameliorates trimethyltin-induced neuronal damage in vivo by attenuating oxidative stress in the dentate gyrus of mice. Biol Pharm Bull. 2011; 34: 1856-63.

30. Pompili E, Fabrizi C, Nori SL, Panetta B, Geloso $\mathrm{MC}$, Corvino V, et al. Protease-activated receptor-1 expression in rat microglia after trimethyltin treatment. J Histochem Cytochem. 2011; 59: 302-11.

31. Eskes C, Juillerat-Jeanneret L, Leuba G, Honegger $\mathrm{P}$, Monnet-Tschudi F. Involvement of microglia-neuron interactions in the tumor necrosis factor-alpha release, microglial activation, and neurodegeneration induced by trimethyltin. J Neurosci Res. 2003; 71: 583-90.

32. Figiel I, Dzwonek K. TNF alpha and TNF receptor 1 expression in the mixed neuronal-glial cultures of hippocampal dentate gyrus exposed to glutamate or trimethyltin. Brain Res. 2007; 1131: 17-28.

33. Röhl C, Sievers J. Microglia is activated by astrocytes in trimethyltin intoxication. Toxicol Appl Pharm. 2005; 204: 36-45.

34. Gebicke-Haerter PJ. Microglia in neurodegeneration: molecular aspect. Microsc Res Tech. 2001; 54: 47-58.

35. Rushaniya AK, Rodrigo MV, Jing D, Husseini KM. A potential role for pro-inflammatory cytokines in regulating synaptic plasticity in major depressive disorder. Int J Neuropsychopharmacol. 2009; 12: 561-78.

36. Himmerich H, Fischer J, Bauer K, Kirkby KC, Sack U, Krügel U. Stress-induced cytokine changes in rats. Eur Cytokine Netw. 2013; 24(2): 97-103.

37. Krügel U, Fischer J, Radicke S, Sack U, Himmerich $H$. Antidepressant effects of TNF- $\alpha$ blockade in an animal model of depression. J Psychiatr Res. 2013; 47: 611-6.

38. Hashimoto R, Takei N, Shimazu K, Christ L, Lu B, Chuang DM. Lithium induces brain-derived neurotrophic factor and activates TrkB in rodent cortical neurons: an essential step for neuroprotection against glutamate excitotoxicity. Neuropharmacology. 2002; 43: 1173-9. 